\title{
Genetic Diversity of Stenocarpella maydis in the Major Corn Production Areas of the United States
}

Martha P. Romero Luna and M. Catherine Aime, Department of Botany and Plant Pathology, Purdue University, West Lafayette, IN 47907; Martin I. Chilvers, Department of Plant, Soil and Microbial Sciences, Michigan State University, East Lansing 48824; and Kiersten A. Wise, ${ }^{\dagger}$ Department of Botany and Plant Pathology, Purdue University

\begin{abstract}
The fungus Stenocarpella maydis (Berk.) B. Sutton, causal agent of Diplodia ear rot, is a prevalent corn (Zea mays L.) pathogen in the United States. Although $S$. maydis reduces grain quality, causes yield loss, and can produce mycotoxins in some countries, few studies have examined its biology and genetic diversity. We analyzed the genetic diversity of 174 S. maydis isolates sampled across the major corn production areas in the United States using nine different microsatellites. In all, 55 unique multilocus genotypes (MLG) were observed out of the 174 S. maydis isolates tested. After conducting a Bayesian clustering analysis by STRUCTURE, it was observed that the most probable number of genetic

groups was two; however, no separation by their geographical location was identified. According to the minimum spanning network, the S. maydis population is linked across geographic regions of the United States but also contains private genotypes. Temporal diversity in the inoculum source was also observed at one location across 4 years. The haploid stage of $S$. maydis was confirmed and both mating type genes were amplified among selected isolates with unique MLG. We theorize that, although $S$. maydis is primarily an asexual fungus, sporadic cryptic recombination may occur, which could contribute to the genetic diversity observed in this study.
\end{abstract}

Stenocarpella maydis (Berk.) B. Sutton, causal agent of Diplodia ear rot, was identified as a corn (Zea mays L.) pathogen in 1909 (Burrill and Barrett 1909) and was recognized as the most important ear rot disease at that time due to severe reductions in yield and grain quality. Stenocarpella maydis has only been reported to reproduce asexually via conidia and survives as mycelia or pycnidia on corn residue (Casa et al. 2006; Sutton and Waterston 1966; Vincelli 1997). Under warm and humid conditions, pycnidia release conidia in cirri (Morant et al. 1993; Moremoholo and Shimelis 2009). These conidia are disseminated by wind and rain to the base of the ear axis (Casa et al. 2004), where infection generally starts within 21 days after silking (Bensch 1995). According to Casa et al. (2004), conidia dissemination is typically limited to $120 \mathrm{~m}$ from the inoculum source, and $S$. maydis is considered a monocyclic pathogen (Van Rensburg and Flett 2010). Corn ears infected by $S$. maydis will have a bleached husk and white fungal mycelia covering the ear. Pycnidia may be observed on the husk or within kernel channels (Casa et al. 2006). Although infection can also occur on leaves and stalks, no correlations among infection between leaf and ear tissue have been reported.

Although the disease was prominent during the early 1900s, its presence declined significantly during the 1970 s due to planting of hybrids with genetic resistance to Diplodia ear rot (Hooker and White 1976) but increased again during the early 1980s and 1990s (Vincelli 1997). Latterell and Rossi (1983) suggested that changes in the corn production system and the absence of truly resistant hybrids contributed to the increased disease occurrence observed during the 1980s. Dorrance et al. (1999) suggested that a change in pathogen virulence could have resulted in its resurgence. Diplodia ear rot continues to persist, with multiple outbreaks occurring during the 2000s across the Midwest (Bradley 2009; Malvick 2001; White and Malvick 2001), resulting in total yield losses of an estimated 3.7 million metric tons across 24 states in the United States and one province (Ontario) in Canada in 2016 (Mueller et al. 2016).

\section{${ }^{\dagger}$ Corresponding author: K. A. Wise; E-mail: kawise@purdue.edu}

*The $\boldsymbol{e}$-Xtra logo stands for "electronic extra" and indicates that two supplementary tables are published online.

Accepted for publication 16 July 2017.

C) 2017 The American Phytopathological Society
Despite the persistence of $S$. maydis in corn fields across the United States, there is limited information on pathogen genetic diversity, which may influence disease severity and affect the efficacy of host resistance in disease management. The most recent study on genetic diversity among $S$. maydis isolates was completed by Dorrance et al. (1999). In that study, $46 \mathrm{~S}$. maydis isolates from the United States and South Africa were evaluated for morphological differences, and isoenzyme polymorphisms for 10 enzymes. Although $S$. maydis isolates did not demonstrate significant isoenzyme variation, isolates varied in morphological characteristics such as the abundance of pycnidia produced and mycelia color. The authors concluded that the lack of isoenzyme variation could be due to the limited host range of $S$. maydis, which includes corn, teosinte (Z. mays subsp. parviglumis), and bamboo (Arundinaria spp.), as well as genetic bottlenecks caused by the use of resistant hybrids. A lack of isolate variation is also common in pathogens with a limited host range (Hellmann and Christ 1991) but, according to Kappelman et al. (1965) and Young et al. (1959), S. maydis isolates vary in virulence. In these studies, local isolates had increased virulence on hosts, compared with isolates obtained from geographically distinct locations. This could indicate that local diversity influences disease severity.

Microsatellite markers, also known as simple sequence repeats (SSR), are usually codominant markers that are often species specific, multiallelic (Field and Wills 1996), and highly polymorphic, and can be easily amplified with specific polymerase chain reactions (PCR) (Morgante and Olivieri 1993). Even though SSR have been widely used to study genetic diversity in fungi because of their abundance and even distribution in the genome (Avis 2004), no studies have applied these markers to examine the genetic diversity of S. maydis.

The objectives of this study were to determine whether differences among $S$. maydis isolates exist across the major corn production areas in the United States and, if so, determine whether $S$. maydis isolates are geographically structured or attributable to asexual propagation (Masango et al. 2014; Sutton and Waterston 1966). Mating type (MAT) was determined. In addition, a study was conducted to evaluate the diversity and dissemination of $S$. maydis inoculum within one location over multiple years.

\section{Materials and Methods}

Fungal isolates and growth conditions. S. maydis isolates were collected from corn fields across the United States between 2010 
and 2015 (Table 1). Isolate background and collection locations are listed in Table 1. Isolates were obtained from infected corn ears (164 isolates) or leaves (10 isolates) based on a previously established protocol (Romero and Wise 2015). Briefly, corn plant tissue was disinfested with 5\% commercial bleach (a.i. 5.05\% sodium hypochlorite), with one drop of Tween 20 added (Bio-Rad Laboratories, Hercules, CA) for $10 \mathrm{~s}$. Tissue was washed twice with sterile water, dried for $4 \mathrm{~h}$, and transferred to natural oatmeal agar (NOA) (Romero Luna 2012). Cultures were stored at $28^{\circ} \mathrm{C}$ under 12-h light-and-dark cycles until pycnidia were visible on the medium (approximately 7 days). A single pycnidium was hand-picked with a sterile needle and placed into a 1.5-ml Flex-Eppendorf tube (Eppendorf AG, Hamburg, Germany) with $150 \mu$ l of nuclease-free sterile water. After agitation, four drops of the suspension were transferred with a sterilized pipette to water agar containing Bacto agar (Becton, Dickinson and Company, Sparks, MD) at $20 \mathrm{~g} /$ liter. Plates were incubated at room temperature for $24 \mathrm{~h}$ in the dark. Single germinated conidia were recovered and transferred to NOA plates, which were incubated at $28^{\circ} \mathrm{C}$ under 12 -h light-and-dark cycles until the plate was fully colonized (approximately 7 days). Once a single-spore culture was obtained, DNA extractions were performed. An S. maydis speciesspecific PCR assay was used to confirm the identity of all putative isolates before microsatellite analysis (Romero and Wise 2015). This method can identify $S$. maydis isolates from pure culture by targeting part of the internal transcribed spacer (ITS) region (GenBank accession number KP164561). After confirming $S$. maydis identity, each isolate was placed in long-term storage in nuclease-free sterile water at $-20^{\circ} \mathrm{C}$, following a previously established protocol (Romero and Wise 2015).

DNA extraction. DNA extraction from $S$. maydis isolates was performed using a previously established protocol (Romero and Wise 2015). DNA was extracted from each stored isolate. DNA was measured with a Nanodrop 1000 spectrophotometer (Thermo Fisher Scientific, Wilmington, DE), and concentrations were adjusted to $10 \mathrm{ng} / \mu \mathrm{l}$ for further analysis.

Development of microsatellite markers, primer design, and screening for polymorphism. A genome sequence of $S$. maydis strain A1-1 was obtained from C. P. Woloshuk (Purdue University). The S. maydis strain A1-1 was obtained from an infected corn ear collected in 2009 from a field in Tippecanoe County, Indiana. The genome assembly consisted of 15,753 contigs (N50 $=9,674$ bp). For this study, a reference genome was assembled by selecting contigs larger than 2,000 kb, which yielded 5,678 contigs (C. P. Woloshuk, unpublished). These were submitted to the Purdue Genomic Center for SSR prediction. The program Primer3 (Koressaar and Remm 2007) was used to design 189 primer pairs flanking microsatellites located in different contigs in the $S$. maydis genome. To design primers flanking SSR, two Perl scripts included within the MISA software package were used, which serve as interface modules for the program-to-program data interchange between MISA and Primer3. The Primer3 parameters were $20 \mathrm{bp}$ in length, 57 to $62^{\circ} \mathrm{C}$ in melting temperature, and 100 to $200 \mathrm{bp}$ in product size. The script p3_in.pl was used to format MISA files to be used as input files for Prime3 and p3_out.pl was used to calculate and merge the information.

From the 189 microsatellite loci, 117 had one nucleotide motif, 58 contained two or more nucleotide motifs, and 14 had a complex nucleotide motifs. For this study, 58 microsatellite loci containing two or more nucleotide motifs were initially screened for polymorphism against eight exemplar isolates of $S$. maydis collected during different years and from different U.S. locations (Table 1). Microsatellite loci were prepared for fragment analysis using a modified M13 method (Díaz-Valderrama and Aime 2016; Schuelke 2000). Each forward SSR primer had an 18-bp tail added to their $5^{\prime}$ ends with the universal M13 primer (5'TGTAAAACGACGGCCAGT-3'), which was previously $5^{\prime}$ labeled with the specific 6-FAM fluorescent dye from the DS-33 dye set (Applied Biosystems, Carlsbad, CA). PCR amplifications were carried out in a final volume of $20 \mu$ l containing $1 \mu \mathrm{l}$ (10 ng) of DNA, $2.5 \mu \mathrm{l}$ of 1× PCR buffer (New England BioLabs, Inc., Ipswich, MA), $0.5 \mu l$ of each dNTP (Promega Corp., Madison, WI), $0.9375 \mu \mathrm{l}$ of 6-FAM, $0.3125 \mu \mathrm{l}$ of the forward primer with
M13 $5^{\prime}$ tail, $1.25 \mu \mathrm{l}$ of reverse primer, $0.5 \mu \mathrm{l}$ of Taq DNA polymerase (New England BioLabs, Inc.), and $11.5 \mu \mathrm{l}$ of nuclease-free sterile water. Thermal cycling included $94^{\circ} \mathrm{C}$ for $5 \mathrm{~min}$; 30 cycles of $94^{\circ} \mathrm{C}$ for $30 \mathrm{~s}, 57^{\circ} \mathrm{C}$ to $62.5^{\circ} \mathrm{C}$ (annealing temperature varied depending on primer used) for $45 \mathrm{~s}$, and $72^{\circ} \mathrm{C}$ for $45 \mathrm{~s} ; 8$ cycles of $94^{\circ} \mathrm{C}$ for $30 \mathrm{~s}, 53^{\circ} \mathrm{C}$ for $45 \mathrm{~s}$, and $72^{\circ} \mathrm{C}$ for $45 \mathrm{~s}$; and finally 1 cycle of $72^{\circ} \mathrm{C}$ for $10 \mathrm{~min}$. PCR products were diluted $1 / 50$, and $2 \mu \mathrm{l}$ of that aliquot was transferred to a plate prefilled with $10 \mu \mathrm{l}$ of a solution of $15 \mu \mathrm{l}$ of GeneScan-500 LIZ (Applied Biosystems) in $1.2 \mathrm{ml}$ of Hi-Di Formamide, and separated by capillary electrophoresis on an ABI 3730XL Genetic Analyzer (Applied Biosystems) at the Purdue Genomics Facility.

After this preliminary screening, nine microsatellite loci were selected based on the ability to amplify across all the tested isolates. The selected microsatellite loci were tested twice against the eight exemplar isolates for reproducibility and used to analyze the remaining 166 isolates using the same methodology. These microsatellite marker sequences were deposited in GenBank under the accession numbers KU588407 to KU588415 (Table 2).

Population genetic diversity. Allele size of the microsatellite amplicons was scored using Peak Scanner software (Applied Biosystems) (Supplementary Table S1). Haploid data were converted into pseudodiploid, and allele binning was performed with TANDEM v1.09 (Matschiner and Salzburger 2009).

Summary statistics for genetic and genotypic diversity were estimated with the Nei's unbiased gene diversity (Nei 1978) and the Shannon-Wiener index of genotypic diversity (Shannon 2001) with poppr package in $\mathrm{R}$ (Kamvar et al. 2014). In addition, to determine whether the number of microsatellite loci selected represented the genotypic diversity of the $S$. maydis population, the relationship between the number of loci and genotype diversity was assessed using the poppr function "genotype_curve". To examine the relationships among isolates, a minimum spanning network was constructed using the genetic distance of Bruvo et al. (2004) with the poppr package in R. Genetic distance matrices were calculated for all the U.S. $S$. maydis isolates. A distance of 0.10 is equivalent to one mutational step. Evidence of recombination was examined by calculating the index of association $\left(I_{\mathrm{A}}\right.$; Brown et al. 1980) and its standardized form $\left(\overline{\mathrm{r}}_{\mathrm{d}}\right.$; Agapow and Burt 2001). Both calculations were estimated with the poppr package in $\mathrm{R}$ from 1,000 permutations, in the full data (174 S. maydis isolates), and in clone-corrected data (70 S. maydis isolates). Clone-corrected data consisted of omitting isolates of the same genotype within the state of origin.

Population structure was also investigated using the Bayesian clustering software STRUCTURE v2.3 (Pritchard et al. 2000). Ten runs for each $K$ ranging from 1 to 10 were done for 100,000 iterations after a burn-in period of 20,000 . The $\lambda$ was set to 1.0 and an admixture model was assumed. To facilitate selection of the most appropriate $K, \Delta K$ (Evanno et al. 2005) was calculated with the web-based program STRUCTURE-HARVESTER (Earl 2012). The 10 replicated runs of the optimal $K$ were combined and visualized using CLUMPAK (Kopelman et al. 2015).

Table 1. Number of Stenocarpella maydis isolates collected by state used in population analysis studies

\begin{tabular}{lc}
\hline State & Number of isolates \\
\hline Indiana & $98^{\mathrm{a}}$ \\
Illinois & $27^{\mathrm{a}}$ \\
Missouri & $8^{\mathrm{a}}$ \\
New York & $5^{\mathrm{a}}$ \\
Iowa & 11 \\
Mississippi & 7 \\
Tennessee & 11 \\
Arkansas & 2 \\
Kentucky & 2 \\
Michigan & 2 \\
Nebraska & 1 \\
\hline
\end{tabular}

${ }^{\text {a }}$ Selected isolates used in the initial screening of microsatellite markers. 
Inoculum dissemination within one Indiana location. In total, $59 \mathrm{~S}$. maydis isolates were obtained during a period of 4 years from corn fields located within an area of $4.6 \mathrm{~km}^{2}$ in Tippecanoe County, IN (Table 1). The location was selected based on the presence of S. maydis over a period of several years. Arbitrary sampling was conducted when corn plants reached physiological maturity and immediately prior to harvest from ears exhibiting symptoms of ear rot as a result of $S$. maydis. In all, 41 isolates were obtained from 2010, 6 from 2012, 5 from 2013, and 7 from 2014 (Supplementary Table S1). Isolate presence was tied to presence of Diplodia ear rot in each year. Years with environmental conditions conducive for disease development produced more isolates than years less favorable for Diplodia ear rot such as 2011. Isolates were obtained using methods as described above. The purpose of this analysis was to test whether the inoculum source each year belonged to either one or multiple multilocus genotypes (MLG). The analysis was conducted using Bruvo genetic distance which, by using a stepwise mutation model for microsatellite loci, reports the relationship shared among isolates. This relationship was visualized by a bootstrap neighbor-joining tree with poppr package in $\mathrm{R}$. The 59 strains collected in this experiment were included in the larger group of 174 isolates collected from across the United States.

Screening for MAT genes. Preliminary results from the population genetic and genotypic diversity analyses suggested the occurrence of sexual reproduction among $S$. maydis isolates. To analyze the contribution of possible sexual reproduction to the genotypic diversity observed, the $S$. maydis genome sequence was screened for the presence of MAT genes, which have not previously been reported in S. maydis. To identify the MAT genes in $S$. maydis, the sequence of a MAT1-1 gene encoding a protein with an $\alpha$ domain and a MAT1-2 gene encoding a protein with the HMG domain of Magnaporthe grisea (GenBank accession numbers BAC65083.1 and XP_003720722.1, respectively) were used as query sequences in tBLASTn searches of the $S$. maydis genomic sequence. The top hits of each gene were located on the same 20-kb contig (GenBank accession number KU588406). To choose primers for the PCR-based mating-type determination assay. MAT1-1 and MAT1-2 genes of $S$. maydis were aligned using MAFFT (Katoh and Standley 2013) (Table 3). A sample of 60 isolates that differed in genotype were intentionally selected and used to corroborate the presence of mating genes (Supplementary Table S2). PCR was conducted in a $20-\mu 1$ reaction volume containing template DNA at $10 \mathrm{ng} / \mathrm{ml}, 0.25 \mathrm{mM}$ each deoxynucleoside triphosphate (Promega Corp.), Taq DNA polymerase (New England BioLabs, Inc.) at $4 \mathrm{U} / \mu 1,1 \times$ PCR buffer (New England BioLabs, Inc.), $0.75 \mathrm{mM}$ forward primer, $0.75 \mathrm{mM}$ reverse primer, and $11 \mu \mathrm{l}$ of nuclease-free sterile water (Thermo Fisher Scientific Inc., Waltham, MA). Fragments were amplified under the following program: an initial heating cycle of $95^{\circ} \mathrm{C}$ for $2 \mathrm{~min} ; 30$ cycles of denaturation at $95^{\circ} \mathrm{C}$ for $30 \mathrm{~s}$, primer annealing at $53^{\circ} \mathrm{C}(\mathrm{Mat} 1 \mathrm{~F} /$ Mat1R) or $55^{\circ} \mathrm{C}$ (Mat2F/Mat2R) for $30 \mathrm{~s}$, and extension at $72^{\circ} \mathrm{C}$ for $40 \mathrm{~s}$; and a 10 -min final extension at $72^{\circ} \mathrm{C}$. Each total product volume $(10 \mu \mathrm{l})$ was loaded on a $1 \%(\mathrm{wt} / \mathrm{vol})$ agarose gel with $1 \times$ Tris-acetateEDTA buffer and stained with ethidium bromide. The gels were run at $100 \mathrm{~V}$ for $20 \mathrm{~min}$ and visualized using a UV-transilluminator FBTI-88 (Thermo Fisher Scientific Inc., Waltham, MA). From 12 isolates, PCR products of each mating gene were sent to the Purdue Genomics Facility for sequencing. Sequences were analyzed and aligned in Sequencher (v 5.2.3; Ann Arbor, MI; http://www.genecodes.com).

\section{Results}

Population genetic diversity. For the nine polymorphic loci, the unbiased gene diversity $(h)$ ranged from 0.011 to 0.572 , and two, three, five, or six alleles were detected per locus. Among the 174 $S$. maydis isolates, 55 MLG were identified, of which 36 were represented by a single isolate. MLG 55 represented $21 \%$ of the data set and included 37 isolates. Based on the Nei's unbiased gene diversity and Shannon-Wiener index of genotypic diversity, the U.S. S. maydis isolates collected in this study have a genetic diversity of 0.302 and a genotypic diversity of 3.198. The genotype accumulation curve indicated that, with eight microsatellites, $90 \%$ of the genotypes from the $S$. maydis population could be identified (data not presented).

The minimum spanning network revealed no distinct pattern of genotype by location, with genotypes from Indiana being present across the network. Bruvo's genetic distance values were low, ranging from close to $0(0.056)$ to 0.139 . Private genotypes were observed in the middle and the edge of the network from Arkansas, Illinois, Indiana, Michigan, Mississippi, and Nebraska. Although these states harbor private genotypes, they have also shared genotypes with other states, except for Michigan and Nebraska. Arkansas, Mississippi, and Tennessee shared genotypes but only Tennessee and Kentucky shared genotypes with states from the Midwest (Fig. 1). After conducting the STRUCTURE analysis, the Evanno $\Delta K$ method supported two clusters but clusters did not strictly separate isolates based on their geographic origin (data not presented). Except for New York isolates, all states had at least one isolate in each identified cluster. These findings provided additional evidence that the U.S. S. maydis isolates are not geographically structured.

The $\mathrm{I}_{\mathrm{A}}$ and its standardized form $\left(\overline{\mathrm{r}}_{\mathrm{d}}\right)$ were significant when no clonal correction was conducted (Table 4), supporting the hypothesis

Table 2. Stenocarpella maydis microsatellite characteristics, including sequence identification, location, repeat motif, forward and reverse primers, product size in number of base pairs (bp), and number of alleles observed

\begin{tabular}{lllllccc}
\hline ID $^{\mathbf{a}}$ & Location & Repeat motif & \multicolumn{1}{c}{ Forward primer } & \multicolumn{1}{c}{ Reverse primer } & Temp $\left({ }^{\circ} \mathbf{C}\right)^{\mathbf{b}}$ & Product size $(\mathbf{b p})^{\text {Alleles }(\boldsymbol{n})}$ \\
\hline 4 & Contig_1661 & (CG)10 & TAAAGGATACGGGCGAACAC & CACGCAATAGCGAAACTCAA & 57 & 251 \\
9 & Contig_2935 & (TG)10 & TTGGGTTGCCCAACTTACTC & TGACGACTTGCAGGAATCAG & 60 & 218 \\
10 & Contig_2994 & (CA)7 & TGGCAACATAAGGTGTGAGC & CCGTGGCAGAGTGGTCTAAT & 57 & 2 \\
18 & Contig_6275 & (CA)6 & ATCTCAAAGCGAGCGATGTT & AAAACCCGCGTACACAGTTC & 60 & 260 \\
42 & Contig_463 & (AGC)5 & CGCAAAACAATCATGTACCG & CGTGTCTCAGAGGGAAAAGC & 57 & 227 \\
46 & Contig_5611 & (TAA)6 & GGGCTCACGATAGCATCAAT & GTCTAGCTATGAGCGCCAGG & 62.5 & 216 \\
54 & Contig_572 & (CCCAG)7 & GCCTCAACGCTCAAAGAAAC & CTTCTCTATGGCTGGCCTTG & 61.4 & 213 \\
55 & Contig_152 & (CTTTT)5 & CTCCTGGGAAAGTCATGGAA & ACCACCAACACCTCCAAGAG & 60 & 280 \\
56 & Contig_132 & (TTTCT)8 & CCCAATACAAGCCACCTGTT & GCTCCGGTTTATGTTCGGTA & 61.4 & 225 & 223 \\
\hline
\end{tabular}

${ }^{a}$ Sequences of microsatellite loci were submitted to GenBank (KU588407 to KU588415).

$\mathrm{b}$ Annealing temperature.

Table 3. Primer sequence used to identify mating type genes of Stenocarpella maydis isolates ${ }^{\mathrm{a}}$

\begin{tabular}{llcccc}
\hline Primer & \multicolumn{1}{c}{ Forward primer } & Reverse primer & Temp $\left({ }^{\circ} \mathbf{C}\right)$ & Product size (bp) & Mating gene \\
\hline Mat1F/R & GAT GAT ATC GGT GGA CAA ATC & GTC ATC ATA CCC GTC TTC TAC & 53 & 203 & $M A T 1-1$ \\
Mat2F/R & CTT CGC CGT TGG TCA TTG TG & GTC ATC ATA CCC GTC TTC TAC & 55 & 369 & $M A T 1-2$ \\
\hline
\end{tabular}

\footnotetext{
a Sequence of the mating genes MAT1-1 and MAT1-2 were submitted to GenBank (KU588406).

b Annealing temperature.
} 
that alleles are effectively linked across loci by clonal reproduction. However, when clonal correction was conducted, $\mathrm{I}_{\mathrm{A}}$ and $\overline{\mathrm{r}}_{\mathrm{d}}$ were not significant (Table 4), a finding that suggests the occurrence of sexual recombination.

Inoculum dissemination within one Indiana location. Based on the analysis conducted with Bruvo's distance, the source of inoculum from the Indiana location indicates that it originates from multiple genotypes and not from a single source (Fig. 2). Three clades were identified that contained isolates from different years, indicating that collected isolates were not grouped based on collection year. After analyzing the MLG of each isolate, it was observed that isolates were placed in clades when they have identical MLG. The MLG of the largest clade, which contains 14 isolates, was used as the starting point to analyze the similarity of the rest of the isolates. Isolates were distanced when allele sizes differed within a locus.

Screening for MAT genes. Putative MAT genes were amplified in all $S$. maydis isolates tested. Amplifications are represented by a band of size, $203 \mathrm{bp}$ for MAT1-1 and $369 \mathrm{bp}$ for MAT1-2 (data not presented). No sequence differences were observed for the putative MAT genes of the 12 isolates.

\section{Discussion}

This is the first study analyzing the genetic diversity of U.S. $S$. maydis isolates using microsatellites. The results obtained from the genetic diversity and population structure analyses indicated that, although repeated MLG were observed among the collected isolates, genetic and genotypic diversity exists among $S$. maydis isolates in the United States. S. maydis isolates were observed to be closely linked in the minimal spanning network; however, S. maydis isolates do not have a defined geographical structure. Although $S$. maydis conidia are disseminated by wind and rain, the extent of their dispersal has previously been reported to be limited (Bensch et al. 1992; Casa et al. 2004; Ullstrup 1958). According to Casa et al. (2006), infested seed can also serve as a source of primary inoculum. Under this pathway, it has been assumed that $S$. maydis has been distributed to other locations as well as introduced to new areas (Casa et al. 2006; Siquiera et al. 2014). In other pathogens such as Mycosphaerella graminicola (Banke and McDonald 2005) and Ascochyta rabiei (Nourollahi et al. 2011), it is suspected that trade and distribution of infested seed has influenced pathogen population differentiation and the distribution of genotypes. The widespread and sometimes shared genotypes of $S$. maydis across the United States regardless of the isolate source of origin could potentially be explained by the movement of infested seed across corn production areas. Diversity in the inoculum source was also observed at one location in Indiana

Table 4. Indices of association $\left(I_{A}\right)$ and its standardized form $\left(\overline{\mathfrak{r}}_{\mathrm{d}}\right)$ for nonclone-corrected and clone-corrected data from the United States population of Stenocarpella maydis

\begin{tabular}{lcc}
\hline \multirow{2}{*}{ Indices } & \multicolumn{2}{c}{ Stenocarpella maydis data type $\mathbf{a}^{\mathbf{a}}$} \\
\cline { 2 - 3 } & Full data & Clone corrected $^{-}$ \\
\hline Number of samples & 174 & 70 \\
Index of association $\left(I_{\mathrm{A}}\right)$ & $0.37(P=0.0009)$ & $0.04(P=0.2897)$ \\
Standardized form of $I_{\mathrm{A}}\left(\overline{\mathrm{r}}_{\mathrm{d}}\right)$ & $0.05(P=0.0009)$ & $0.01(P=0.2897)$ \\
\hline
\end{tabular}

${ }^{a} P$ values were determined by 1,000 randomizations.

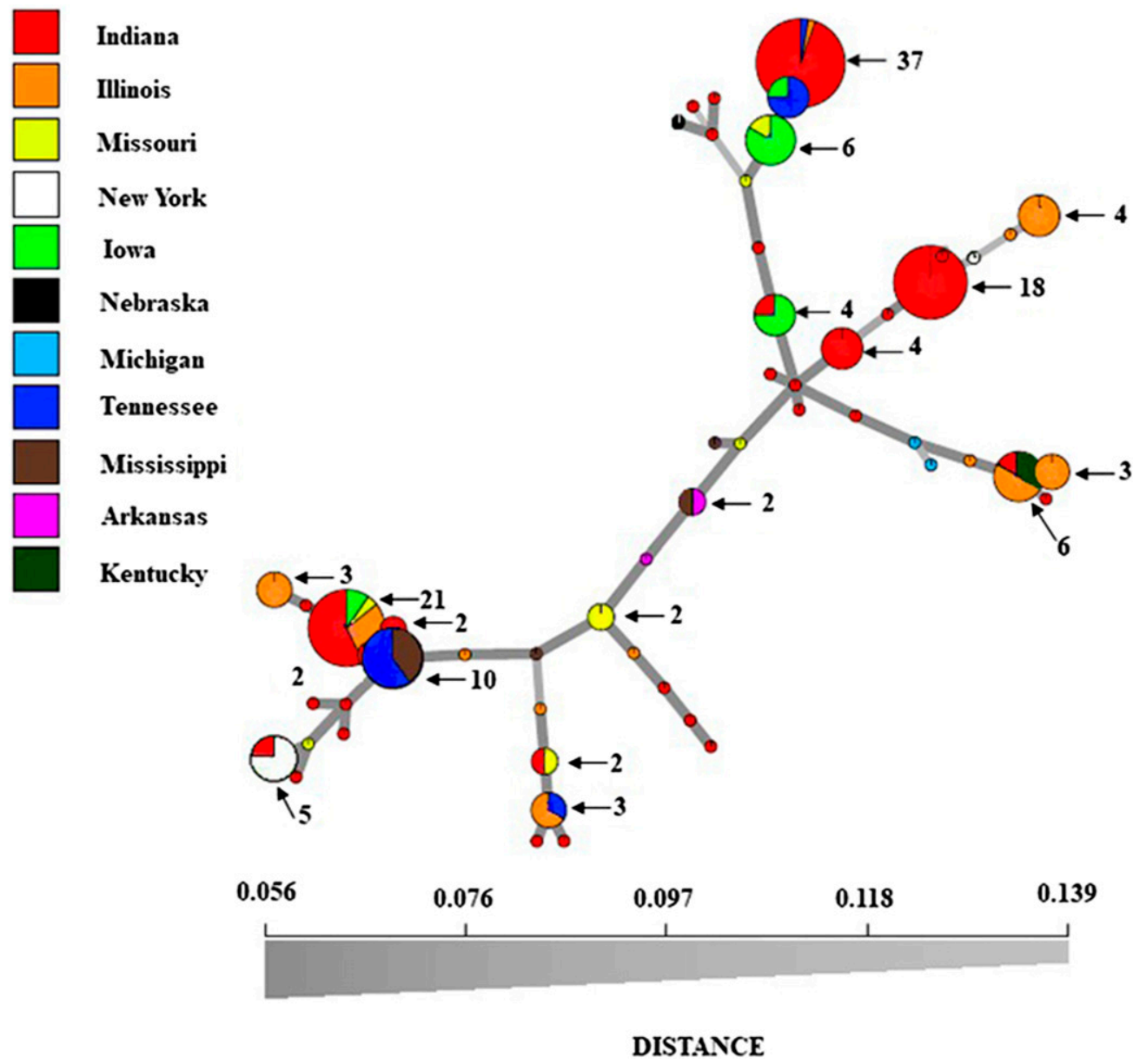

Fig. 1. Minimal spanning network for the United States Stenocarpella maydis population based on Bruvo's genetic distance. Circles represent individual multilocus genotypes and each color represents one of the states where $S$. maydis isolates were collected. A number outside the circle connected by an arrow indicates the number of isolates associated with that genotype. Lines represent minimum genetic distance between isolates. Closely related genotypes have a darker and thicker line; length is arbitrary. 
over multiple years, indicating that different genotypes have been introduced to the area over the study years, potentially through planting infested seed produced in another location that contains a different genotype and by the occurrence of genetic recombination among the local genotypes. The role of infested seed in local and national diversity of $S$. maydis requires additional investigation to determine whether this is a significant source of pathogen movement and to better understand how this influences pathogen diversity.

A previous study by Dorrance et al. (1999) using an isoenzyme analysis to assess polymorphism among $46 \mathrm{~S}$. maydis isolates collected from the United States and South Africa indicated low variation among $S$. maydis isolates. However, our study determined that variation among $S$. maydis isolates exists, regardless of origin. We believe that our findings differ from those of Dorrance et al. (1999) due to the differences in discriminatory power of the markers used in each study. Although isoenzymes and microsatellites are both codominant molecular markers, studies using both molecular markers have observed a greater level of polymorphism with microsatellites than with isoenzymes (Da Costa-Ribeiro et al. 2006; Karasawa et al. 2012; Kumar et al. 2009; Solano et al. 1997). In our study, nine microsatellites were identified as polymorphic molecular markers among S. maydis isolates. Overall, these new microsatellite markers were inexpensive and reproducible among the isolates obtained from a wide sampling area across the United States, and can be used for additional studies to characterize $S$. maydis populations.

According to Milgroom (1996), organisms that are only known to reproduce asexually are expected to have low levels of genetic diversity. We conducted the study with the assumption that $S$. maydis was a haploid organism that solely reproduces asexually; however, when data were subjected to clone correction in the $I_{\mathrm{A}}$ analysis, we rejected
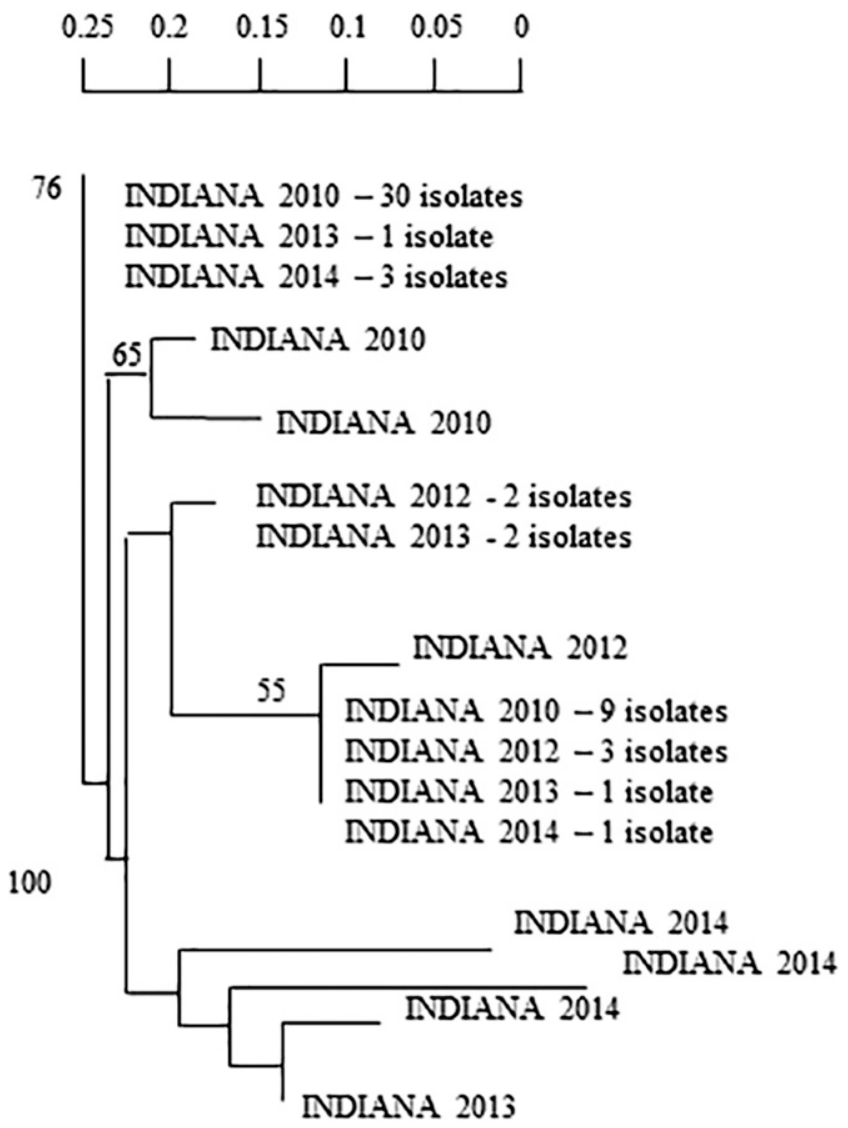

Fig. 2. Rooted neighbor-joining tree with 1,000 bootstrap replicates of Bruvo's genetic distance for the comparison of the Stenocarpella maydis isolates collected across 4 years at the same location in Tippecanoe County, IN. Branches with bootstrap values greater than $50 \%$ are presented. the hypothesis that alleles were linked across loci by clonal reproduction, suggesting that the observed genotypic and genetic diversity in $S$. maydis could be from sexual recombination. Population studies on other asexual fungal plant pathogens such as Rhynchosporium secalis (Salamati et al. 2000), Colletotrichum truncatum (Diao et al. 2015), and Alternaria alternata (Aradhya et al. 2001; Peever et al. 2000) have reported large genotypic variation, which suggests the occurrence of sexual recombination. Even though many fungi are classified as asexual, the production of the sexual stage is possible under specific environmental conditions (Holland 2002; Sun and Heitman 2011). Moreover, it is also possible that a sexual stage in S. maydis has been overlooked (Lucas 2009).

The genetic and genotypic diversity values obtained in this study ( 0.302 and 3.198, respectively) were considered high based on the ranges established in each genetic measure. Nei's unbiased gene diversity index ranges from 0 to 1 (Nei 1978) and Shannon-Wiener from 1.5 to 3.5 (MacDonald 2003). Salamati et al. (2000) reported high genetic diversity, with values ranging from 0.133 to 0.749 , among 8 populations of Rhynchosporium secalis, and the genetic diversity of Colletotrichum truncatum was considered high based on a genetic diversity of 0.458 for 1 among 13 populations (Diao et al. 2015). However, within each population, the genetic diversity differed and, therefore, previous studies were able to determine which population had a greater genetic diversity. To determine whether there is high genetic diversity among our S. maydis populations, more genetic studies are needed within and outside the United States.

The use of MAT gene analysis to confirm or refute sexual recombination in asexual fungi has been conducted in other plant pathogens such as Cercospora spp., (Groenewald et al. 2006), Cladosporium fulvum (Stergiopoulos et al. 2007), Septoria passerinii (Goodwin et al. 2003), Alternaria brassicicola (Linde et al. 2010), Fusarium oxysporum and F. culmorum (Irzykowska and Kosiada 2011), and Moniliophthora roreri (Díaz-Valderrama and Aime 2016). In this study, we identified MAT1-1 and MAT1-2 putative genes in the same contig, and amplified part of each gene in a sample of 60 selected $S$. maydis isolates. The detection of both putative mating genes in all isolates tested could indicate that $S$. maydis is a homothallic species (Taylor et al. 1999). Homothallic species are able to self-fertilize and complete the sexual cycle without a partner (Taylor et al. 1999) but are also capable of outcrossing (Lin and Heitman 2007). Therefore, the variability among $S$. maydis isolates observed in this study could indicate that occasional genetic interchange occurs among $S$. maydis isolates. Although the evidence of outcrossing among S. maydis isolates was suggested by the genetic diversity and population structure analyses, we were not able to corroborate the occurrence of an outcrossing event. Both putative MAT genes were amplified and confirmed among selected $S$. maydis isolates.

Organisms with both asexual and sexual reproduction are more challenging to manage due to the higher evolutionary potential of the organism (McDonald and Linde 2002). Sexual reproduction will create new genotypes which may be better adapted to survive and reproduce asexually (McDonald and Linde 2002), and previous studies have documented differences in pathogenicity and virulence among S. maydis isolates (Kappelman et al. 1965). This information, coupled with our findings, indicates that additional sampling of $S$. maydis across the United States could facilitate the identification of unique genotypes, as well as determine the extent of their distribution in the U.S. corn production areas. These unique genotypes should be screened for differences in pathogenicity and virulence, which would be valuable information when breeding for disease resistance to Diplodia ear rot.

Our results yield new information on the genetic diversity of $S$. maydis. For the first time, the geographic diversity of $S$. maydis was characterized using microsatellite markers, and the presence of both putative MAT genes was reported in this pathogen. Further studies that include a more extensive sample collection are needed to fully understand the genetic diversity of this pathogen, its genotypic variability among different geographic regions, and the possibility of sexual recombination. 


\section{Acknowledgments}

We thank C. P. Woloshuk for providing access to the $S$. maydis genome; T. Allen, G, Bergstrom, C. Bradley, T. Faske, T. Jackson, D. Mullen, C. Niu, L. Sweets, and $\mathrm{H}$. Young-Kelly for providing samples to conduct this study; S. Goodwin for providing helpful guidance during the development of this study; N. Anderson for laboratory assistance; and N. Albright, J. Diaz, R. Koch, and J. Wang for valuable comments and suggestions on the study.

\section{Literature Cited}

Agapow, P. M., and Burt, A. 2001. Indices of multilocus linkage disequilibrium. Mol. Ecol. Notes 1:101-102.

Aradhya, M. K., Chan, H. M., and Parfitt, D. E. 2001. Genetic variability in the pistachio late blight fungus, Alternaria alternata. Mycol. Res. 105:300-306.

Avis, J. C. 2004. Molecular Markers, Natural History, and Evolution, 2nd ed. Sinauer, Sunderland, MA.

Banke, S., and McDonald, B. A. 2005. Migration patterns among global populations of the pathogenic fungus Mycosphaerella graminicola. Mol. Ecol. 14:1881-1896.

Bensch, M. J. 1995. Stenocarpella maydis (Berk) Sutton colonization of maize ears. Phytopathol. Z. 143:597-599.

Bensch, M. J., Vanstaden, J., and Rijkenberg, F. H. J. 1992. Time and site of inoculation of maize for optimum infection of ears by Stenocarpella-maydis. Phytopathol. Z. 136:265-269.

Bradley, C. A. 2009. Diplodia ear rot causing problems in corn across the state. Bull. Univ. Ill. Ext. No. 23, Article 6.

Brown, A. H. D., Feldman, M. W., and Nevo, E. 1980. Multilocus structure of natural populations of Hordeum spontaneum. Genetics 96:523-536.

Bruvo, R. M., D’Souza, T. G., and Schulenburg, H. 2004. A simple method for the calculation of microsatellite genotype distance irrespective of ploidy level. Mol. Ecol. 13:2101-2106.

Burrill, T. J., and Barrett, J. T. 1909. Ear rots of corn. Univ. Ill. Agric. Exp. Stn. Bull. 133:64-109.

Casa, R. T., Reis, E. M., and Zambolim, L. 2004. Dispersao vertical e horizontal de conidios de Stenocarpella macrospora e Stenocarpella maydis. Fitopatol. Bras. 24:141-147.

Casa, R. T., Reis, E. M., and Zambolim, L. 2006. Doenças do milho causadas por fungos do gênero Stenocarpella. Fitopatol. Bras. 31:427-439.

Da Costa-Ribeiro, M. C., Lourenco-de-Oliveira, R., and Failloux, A. B. 2006. Higher genetic variation estimated by microsatellites compared to isoenzyme markers in Aedes aegypti from Riode Janeiro. Mem. Inst. Oswaldo Cruz 101: 917-921.

Diao, Y., Zhang, C., Xu, J., Lin, D., Liu, L., Mtung'e, O. G., and Liu, X. 2015. Genetic differentiation and recombination among geographic populations of the fungal pathogen Colletotrichum truncatum from chili peppers in China. Evol. Appl. 8:108-118.

Díaz-Valderrama, J. R., and Aime, M. C. 2016. The cacao pathogen Moniliophthora roreri (Marasmiaceae) possesses biallelic A and B mating loci but reproduces clonally. Heredity 116:491-501.

Dorrance, A. E., Miller, O. K., and Warren, H. L. 1999. Comparison of Stenocarpella maydis isolates for isozyme and cultural characteristics. Plant Dis. 83:675-680.

Earl, D. A. 2012. STRUCTURE HARVESTER: A website and program for visualizing STRUCTURE output and implementing the Evanno method. Conserv. Genet. Resour. 4:359-361.

Evanno, G., Regnaut, S., and Goudet, J. 2005. Detecting the number of clusters of individuals using the software STRUCTURE: A simulation study. Mol. Ecol. 14:2611-2620

Field, D., and Wills, C. 1996. Long, polymorphic microsatellites in simple organisms. Proc. R. Soc. Lond. Biol. 263:209-215.

Goodwin, S. B., Waalwijk, C., Kema, G. H. J., Cavaletto, J. R., and Zhang, G. 2003. Cloning and analysis of the mating-type idiomorphs from the barley pathogen Septoria passerinii. Mol. Genet. Genomics 269:1-12.

Groenewald, M., Groenewald, J. Z., Harrington, T. C., Abeln, E. C. A., and Crous, P. W. 2006. Mating type gene analysis in apparently asexual Cercospora species is suggestive of cryptic sex. Fungal Genet. Biol. 43:813-825.

Hellmann, R., and Christ, B. J. 1991. Isozyme variation of physiologic races of Ustilago hordei. Phytopathology 81:1536-1540.

Holland, B. 2002. Sexual selection fails to promote adaptation to a new environment. Evolution 56:721-730.

Hooker, A. L., and White, D. G. 1976. Prevalence of corn stalk rot fungi in Illinois. Plant Dis. Rep. 60:1032-1034.

Irzykowska, L., and Kosiada, T. 2011. Molecular identification of mating type genes in asexually reproducing Fusarium oxysporum and F. culmorum. J. Plant Prot. Res. 51:405-409.

Kamvar, Z. N., Tabima, J. F., and Grünwald, N. J. 2014. Poppr: An R package for genetic analysis of populations with clonal, partially clonal, and/or sexual reproduction. PeerJ 2:e281.

Kappelman, A. J., Thompson, D. L., and Nelson, R. R. 1965. Virulence of 20 isolates of Diplodia zeae as revealed by stalk rot development in corn. Crop Sci. 5:541-543.

Karasawa, M. M. G., Vencovsky, R., Silva, C. M., Cardim, D. C., Bressan, E. A., Oliveira, G. C. X., and Veasey, E. A. 2012. Comparison of microsatellites and isozymes in genetic diversity studies of Oryza glumaepatula (Poaceae) populations. Rev. Biol. Trop. 60:1463-1478.
Katoh, K., and Standley, D. M. 2013. MAFFT multiple sequence alignment software version 7: Improvement in performance and usability. Mol. Biol. Evol. 30:772-780.

Kopelman, N. M., Mayzel, J., Jakobsson, M., Rosenberg, N. A., and Mayrose, I 2015. CLUMPAK: A program for identifying clustering modes and packaging population structure inferences across K. Mol. Ecol. Resour. 15:1179-1191.

Koressaar, T., and Remm, M. 2007. Enhancements and modifications of primer design program Primer3. Bioinformatics 23:1289-1291.

Kumar, P., Gupta, V. K., Misra, A. K., Modi, D. R., and Pandey, B. K. 2009 Potential of molecular markers in plant biotechnology. Plant Omics 2:141-162.

Latterell, F. M., and Rossi, A. E. 1983. Stenocarpella macrospora (=Diplodia macrospora) and $S$. maydis (=D. maydis) compared as pathogens of corn. Plant Dis. 67:725-729.

Lin, X., and Heitman, J. 2007. Mechanisms of homothallism in fungi and transitions between heterothallism and homothallism. Pages 35-57 in: Sex in Fungi. J. Heitman, J. Kronstad, J. Taylor, and L. Casselon, eds. ASM Press, Washington, DC

Linde, C. C., Liles, J. A., and Thrall, P. H. 2010. Expansion of genetic diversity in randomly mating founder populations of Alternaria brassicicola infecting Cakile maritima in Australia. Appl. Environ. Microbiol. 76:1946-1954.

Lucas, J. 2009. Plant Pathology and Plant Pathogens, 3rd ed. John Wiley \& Sons, Blackwell, UK.

MacDonald, G. M. 2003. Page 409 in: Biogeography: Introduction to Space, Time, and Life. John Wiley \& Sons, Inc., New York.

Malvick, D. 2001. Diplodia ear rot of corn. Online publication. Bull. Univ. Ill. Ext. http://bulletin.ipm.illinois.edu/pastpest/articles/200120e.html

Masango, M. G., Flett, B. C., Ellis, C. E., and Botha, C. J. 2014. Stenocarpella maydis and its toxic metabolites: A South African perspective on diplodiosis. World Mycotoxin J. 8:341-350.

Matschiner, M., and Salzburger, W. 2009. TANDEM: Integrating automated allele binning into genetics and genomics workflows. Bioinformatics 25:1982-1983.

McDonald, B. A., and Linde, C. 2002. Pathogen population genetics, evolutionary potential, and durable resistance. Annu. Rev. Phytopathol. 40:349-379.

Milgroom, M. G. 1996. Recombination and the multilocus structure of fungal populations. Annu. Rev. Phytopathol. 34:457-477.

Morant, M. A., Warren, H. L., and Von Qualen, S. K. 1993. A synthetic medium for mass production of pycnidiospores of Stenocarpella species. Plant Dis. 77: 424-426.

Moremoholo, L., and Shimelis, H. 2009. Stability analysis for grain yield and Stenocarpella maydis ear rot resistance in maize. Afr. Crop Sci. J. 9:425-433.

Morgante, M., and Olivieri, A. M. 1993. PCR-amplified microsatellites as markers in plant genetics. Plant J. 3:175-182.

Mueller, D., Sisson, D., and Wise, K. A. 2016. Corn disease loss estimates from the United States and Ontario, Canada 2016. Crop Protection Network. CPN 207-16-W.

Nei, M. 1978. Estimation of average heterozygosity and genetic distance from small number of individuals. Genetics 89:583-590.

Nourollahi, K., Javannikkhah, M., Naghavi, M. R., Lichtenzveig, J., Okhovat, S. M., Oliver, R. P., and Ellwood, S. R. 2011. Genetic diversity and population structure of Ascochyta rabiei from the western Iranian Ilam and Kermanshah provinces using MAT and SSR markers. Mycol. Prog. 10:1-7.

Peever, T. L., Olsen, L., Ibañez, A., and Timmer, L. W. 2000. Genetic differentiation and host specificity among populations of Alternaria spp. causing brown spot of grapefruit and tangerine $\times$ grapefruit hybrids in Florida. Phytopathology 90 : 407-414.

Pritchard, J. K., Stephens, M., and Donnelly, P. 2000. Inference of population structure using multilocus genotype data. Genetics 155:945-959.

Romero, M. P., and Wise, K. A. 2015. Development of molecular assays for detection of Stenocarpella maydis and Stenocarpella macrospora in corn. Plant Dis. 99:761-769.

Romero Luna, M. P. 2012. Managing Diplodia ear rot in corn: Short and long-term solutions. M.S. thesis, Purdue University, West Lafayette, IN.

Salamati, S., Zhan, J., Burdon, J. J., and McDonald, B. A. 2000. The genetic structure of field populations of Rhynchosporium secalis from three continents suggests moderate gene flow and regular recombination. Phytopathology 90: 901-908.

Schuelke, M. 2000. An economic method for the fluorescent labeling of PCR fragments. Nat. Biotechnol. 18:233-234.

Shannon, C. E. 2001. A mathematical theory of communication. Mob. Comput Commun. Rev. 5:3-55.

Siquiera, C. D. S., Barrocas, E. N., Machado, J. D. C., Silva, U. A. D., and Dias, I. E. 2014. Effects of Stenocarpella maydis in seeds and the initial development of corn. J. Seed Sci. 36:79-86.

Solano, P., Duvallet, G., Dumas, V., Cuisance, D., and Cuny, G. 1997. Microsatellite markers for genetic population studies in Glossina palpalis (Diptera: Glossinidae). Acta Trop. 65:175-180.

Stergiopoulos, I., Groenewald, M., Staats, M., Lindhout, P., Crous, P. W., and De Wit, P. J. 2007. Mating-type genes and the genetic structure of a world-wide collection of the tomato pathogen Cladosporium fulvum. Fungal Genet. Biol. 44:415-429.

Sun, S., and Heitman, J. 2011. Is sex necessary? BMC Biol. 9:56.

Sutton, B. C., and Waterston, J. M. 1966. Diplodia maydis. In: CMI Descriptions of 525 Pathogenic Fungi and Bacteria. Set 9. No. 84. CAB International, Wallingford, UK. 
Taylor, J. W., Jacobson, D. J., and Fisher, M. C. 1999. The evolution of asexual fungi: Reproduction, speciation and classification. Annu. Rev. Phytopathol. 37:197-246.

Ullstrup, A. J. 1958. A study of the nature of intraspecific aversion in Diplodia maydis. Bull. Torrey Bot. Club 85:397-404.

Van Rensburg, J. B. J., and Flett, B. C. 2010. A review of research achievements on maize stem borer, Busseola fusca (Fuller) and Diplodia ear rot caused by Stenocarpella maydis (Berk. Sutton). S. Afr. J. Plant Soil 27: $74-80$
Vincelli, P. 1997. Ear rot of corn caused by Stenocarpella maydis (=Diplodia maydis). University of Kentucky Cooperative Extension Service publication PPA-43, Lexington, KY. https://www.yumpu.com/s/1mvlhjLDXFw3dEvU

White, D., and Malvick, D. 2001. Diplodia ear rot: An old disease reborn. Online publication. University of Illinois, Urbana. http://agronomyday.cropsci.illinois. edu/2001/tours/diplodia-ear-rot//

Young, H. C. J., Wilcoxson, R. D., Whitehead, M. D., Devay, J. E., Grogan, C. O., and Zuber, M. S. 1959. An ecological study of the pathogenicity of Diplodia maydis isolates inciting stalk rot on corn. Plant Dis. Rep. 43:1124-1129. 